\title{
Montmorillonite- $\mathrm{Cu}(\mathrm{II}) / \mathrm{Fe}(\mathrm{III})$ oxides magnetic material as adsorbent for removal of humic acid and its thermal regeneration
}

\author{
Xianjia Peng ${ }^{\mathrm{a}}$, Zhaokun Luan ${ }^{\mathrm{a}, *}$, Hongmei Zhang ${ }^{\mathrm{b}}$ \\ a State Key Laboratory of Environmental Aquatic Chemistry, Research Center for Eco-Environmental Sciences, \\ Chinese Academy of Sciences, Beijing 100085, China \\ b Department of Chemistry and Environment, China University of Mining Technology, Beijing 100083, China
}

Received 3 September 2004; received in revised form 29 June 2005; accepted 10 July 2005

Available online 5 October 2005

\begin{abstract}
In this work, the adsorption features of montmorillonite and the magnetic properties of $\mathrm{Cu}(\mathrm{II}) / \mathrm{Fe}(\mathrm{III})$ oxides were combined in a material to produce magnetic adsorbent, which can be separated from the medium by a simple magnetic process after adsorption. The magnetic material is effective for the removal of humic acid. At $\mathrm{pH} 6.1,96 \%$ removal was observed from $4.4 \mathrm{mg}^{-1}$ humic acid solution containing $0.02 \mathrm{M} \mathrm{NaCl}$. The adsorption is $\mathrm{pH}$ and ionic strength dependent. Adsorption is favored at lower $\mathrm{pH}$ values and dissolved $\mathrm{NaCl}$ can enhance the adsorption. The adsorption mechanism of humic acid to the magnetic material was suggested to be the ligand exchange reaction between carboxylic groups of humic acid molecules and the magnetic material surface. The magnetic material can be thermally regenerated. The temperature and time required to achieve good regeneration efficiency were determined to be $300{ }^{\circ} \mathrm{C}$ and $3 \mathrm{~h}$, respectively. The regenerated adsorbent is still magnetic and approximately has as high specific saturation magnetization and good adsorption capacities as the as-prepared adsorbent.
\end{abstract}

(C) 2005 Elsevier Ltd. All rights reserved.

Keywords: Water treatment; Adsorption mechanism; Ionic strength; Magnetic separation

\section{Introduction}

Adsorption is an important method employed in water treatment with high removal efficiency and no harmful by-product. Many kinds of adsorbents have been developed for the removal of pollutants from water. Magnetic separation is also a promising technology employed in water treatment because of high sepa-

\footnotetext{
* Corresponding author. Tel./fax: +86 1062849198.

E-mail address: luanzk@mail.rcees.ac.cn (Z. Luan).
}

ration rate using a simple magnetic process. One example of this technology is the use of magnetite particles to accelerate the coagulation of sewage (Booker et al., 1991).

It seems attractive to combine adsorption properties with magnetic properties to produce novel kinds of adsorbents for the removal of pollutants from water. Some research has been done on this issue. Some examples are the use of polyacrylic acid-bound iron oxide magnetic nanoparticles for adsorption of methylene blue (Mak and Chen, 2004), the use of activated carbon/iron oxide magnetic composites for the adsorption of volatile 
organic compounds (Oliveira et al., 2002) and the use of montmorillonite-iron oxide magnetic composites for the adsorption of metal cations (Oliveira et al., 2003).

Like other adsorbents, magnetic adsorbents will eventually become saturated over time. Without regeneration, exhausted magnetic adsorbents would require disposal as solid wastes. In order to minimize this problem and save on adsorbent costs, regeneration is essential. For the regeneration of adsorbents saturated with organic pollutants, a thermal process is usually employed. By a thermal regeneration process, exhausted adsorbents can be recycled and used repeatedly. Furthermore, the adsorbed organic pollutants can be mineralized and will not cause secondary pollution. This is the safest way to the environment.

At present, just a few kinds of magnetic adsorbents have been prepared and the study of magnetic adsorbents for water treatment was carried out for just a few kinds of pollutants. The removal of humic acid using this technology has little been reported. Further, the regeneration of the magnetic adsorbents has little been investigated. In the previous study, the magnetic components of magnetic adsorbents are generally $\mathrm{Fe}(\mathrm{II}) / \mathrm{Fe}$ (III) oxides. $\mathrm{Fe}(\mathrm{II}) / \mathrm{Fe}$ (III) oxides will probably lose magnetic properties at high temperature in a thermal regeneration process.

The objective of this research is to develop a new kind of magnetic adsorbent which can be effective for the removal of humic acid and can be regenerated by a thermal process. For this purpose, the adsorption properties of pillared montmorillonite were combined with the magnetic properties of $\mathrm{Cu}(\mathrm{II}) / \mathrm{Fe}$ (III) oxides to produce montmorillonite- $\mathrm{Cu}(\mathrm{II}) / \mathrm{Fe}$ (III) oxides magnetic material. Montmorillonite is a naturally occurring, non-hazardous and cost-effective raw material. Pillared montmorillonite, which can be prepared by modifying montmorillonite with an intercalation process, has been studied for the removal of organic pollutants ( $\mathrm{Wu}$ et al., 2001). Our previous research has discovered that, pillared montmorillonite is effective for the removal of humic acid (Peng et al., 2005). Cu(II)/Fe(III) oxides were used as the magnetic components in this research because $\mathrm{Cu}(\mathrm{II}) / \mathrm{Fe}(\mathrm{III})$ oxides will not lose magnetic properties in the thermal regeneration process. In order to immobilize magnetic metal oxides onto the host pillared montmorillonite, the stabilized colloidal dispersions of $\mathrm{Cu}(\mathrm{OH})_{2} / \mathrm{Fe}(\mathrm{OH})_{3}$ in poly(vinyl alcohol) (PVA) was used as an effective system for the magnetic modification of pillared montmorillonite surfaces (Yokoi et al., 1990; Lee et al., 1996). It is because PVA is a potential complexant for the pillaring agent (aluminium polycations, Keggin-like $\mathrm{Al}_{13}$ oligomeric cations) (Skoutelas et al., 1999). The prepared magnetic adsorbent is reported to be effective for the removal of humic acid from water in this paper. After the adsorption is carried out, the adsorbent can be separated from the medium by a simple magnetic process and the exhausted adsorbent can be regenerated by a thermal process.

\section{Experiments}

\subsection{Preparation of the magnetic material}

The procedure followed to prepare the magnetic material was illustrated in Fig. 1. Na-montmorillonite was used as the starting material. The pillaring solution, aluminium polycation, was prepared by adding $0.5 \mathrm{M}$ $\mathrm{NaOH}$ drop by drop to $0.2 \mathrm{M} \mathrm{AlCl}_{3}$ at $85^{\circ} \mathrm{C}$ with a vigorous stirring. The mole ratio of $\mathrm{NaOH} / \mathrm{AlCl}_{3}$ was 2.4 . Pillared montmorillonite was synthesized by adding the pillaring solution (aluminium polycation) drop by drop to a $1.5 \%$ Na-montmorillonite suspension at room temperature with a vigorous stirring. The ratio of aluminium to montmorillonite was $10 \mathrm{mmol} \mathrm{g}^{-1}$. The magnetic dispersion was synthesized by adding $\mathrm{NaOH}$ solution to a mixture of $0.533 \mathrm{~g} \mathrm{CuCl}_{2} \cdot 2 \mathrm{H}_{2} \mathrm{O}, 2.525 \mathrm{~g}$ $\mathrm{Fe}\left(\mathrm{NO}_{3}\right) \cdot 9 \mathrm{H}_{2} \mathrm{O}$ and $0.375 \mathrm{~g}$ PVA in $100 \mathrm{ml}$ water till $\mathrm{pH}=11.0$. The magnetic adsorbent was prepared by mixing the magnetic dispersion with pillared montmorillonite suspension (mass ratio of montmorillonite/ $\left.\left(\mathrm{CuO}+\mathrm{Fe}_{2} \mathrm{O}_{3}\right)=4: 1\right)$. The mixture was stirred for $2 \mathrm{~h}$, aged at $95-100{ }^{\circ} \mathrm{C}$ for $2 \mathrm{~h}$, then centrifuged and washed with deionized water. The obtained solid was dried, milled (particle size $<0.075 \mathrm{~mm}$ ), and calcined at $500{ }^{\circ} \mathrm{C}$ for $2 \mathrm{~h}$. The product obtained was used as magnetic adsorbent.

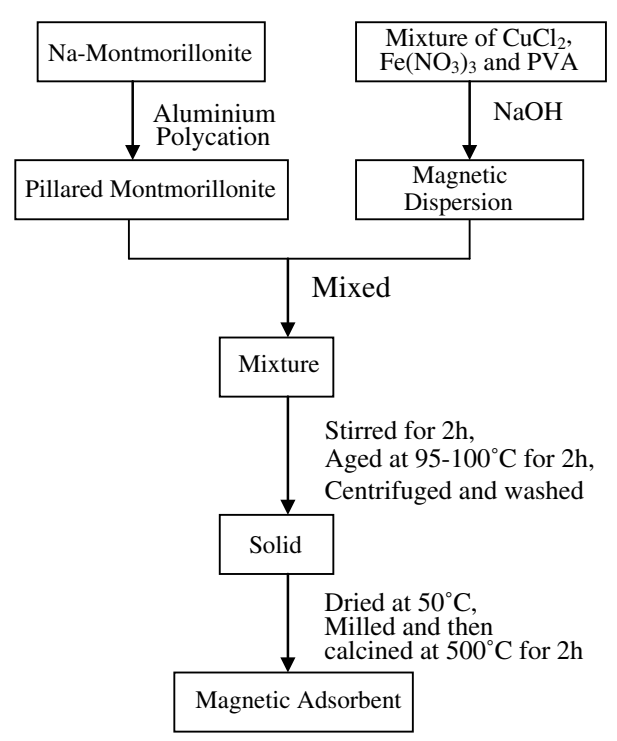

Fig. 1. Preparation pathway for the magnetic material. 


\subsection{Characterization of the magnetic material}

Magnetization measurements were carried out on a LDJ model 9600 vibrating sample magnetometer at room temperature. Zeta potential of the adsorbent was determined by microelectrophoresis using a Malven model Zetasizer 2000 zeta potential analyzer. The zeta potentials of the adsorbents suspensions containing $0.02 \%$ solid in $0.01 \mathrm{M} \mathrm{NaCl}$ were determined at various $\mathrm{pH}$ values. Specific surface areas (SSA) were determined according to the Brunaur-Emmet-Teller (BET) protocol on a Micromeritics model ASAP 2000 accelerated surface area and porosimetry.

\subsection{Adsorption and regeneration experiments}

Humic acid was obtained as a commercial reagent grade solid from Aldrich. Before the adsorption test, the humic acid stock solution was prepared by dissolving a certain amount of humic acid in a known volume of deionized water and then filtered through a $0.45 \mu \mathrm{m}$ membrane filter. The concentration of the solution was determined by deducting the weight of those particles retained on the membrane filter. Batch adsorption experiments were performed in glass bottles. To each bottle, $50 \mathrm{ml}$ humic acid solution of prescribed concentration and adsorbent were added. The $\mathrm{pH}$ was adjusted using $1 \mathrm{M} \mathrm{HCl}$ or $1 \mathrm{M} \mathrm{NaOH}$. The bottles were capped with glass screws and then the mixture was shaken on a HZQ-C shaker at $20^{\circ} \mathrm{C}$ for $3 \mathrm{~h}$. Then the adsorbent was separated from the solution by a magnetic process using a permanent magnet made of $\mathrm{Nd}-\mathrm{Fe}-\mathrm{B}$ and the residual concentrations of humic acid was analysed spectrophotometrically using a Hitachi model U-3010 double beam UV/visible spectrophotometer at $254 \mathrm{~nm}$. Matched $10 \mathrm{~mm}$ quartz cells were used. Humic acid adsorbed was calculated.

For regeneration, first humic acid was adsorbed from a $400 \mathrm{mg}^{-1}$ solution containing $0.02 \mathrm{M} \mathrm{NaCl}$ according to the same procedure described above. Then the spent adsorbent was separated from the mixture by a magnetic process, dried and put into a ceramic crucible and calcined at certain temperature for a certain period of time in an electric muffle furnace under air atmosphere.

\section{Results and discussion}

\subsection{Characterization of the magnetic material}

After preparation, a test with the $\mathrm{Nd}-\mathrm{Fe}-\mathrm{B}$ magnet showed that the whole material was magnetic and completely attracted to the magnet. The specific saturation magnetization $\left(\sigma_{\mathrm{s}}\right)$, SSAs, pore volume and mean pore diameter of montmorillonite and magnetic material are shown in Table 1. The magnetization measurements showed that the $\sigma_{\mathrm{s}}$ is $3.9 \mathrm{emu} \mathrm{g}^{-1}$ (magnetic field = $20000 \mathrm{Oe})$. The SSA of the magnetic material is $115 \mathrm{~m}^{2} \mathrm{~g}^{-1}$ which is much larger than that of montmorillonite. After the magnetic modification, the pore volume climes up from $0.20 \mathrm{ml} \mathrm{g}^{-1}$ to $0.26 \mathrm{ml} \mathrm{g}^{-1}$ and the mean pore diameter decreases from $15.0 \mathrm{~nm}$ to $9.1 \mathrm{~nm}$. The increased SSAs, pore volume and decreased mean pore diameter suggests the formation of microporous system in the magnetic material.

The zeta potentials of the magnetic material at various $\mathrm{pH}$ are shown in Fig. 2. For comparison, zeta potentials of montmorillonite were also included. As can be seen from Fig. 2, zeta potentials of both the magnetic material and montmorillonite decrease with the increase in $\mathrm{pH}$. It can also be seen that the magnetic material has higher zeta potentials than montmorillonite, which indicates that they are less negatively charged. The increased zeta potentials resulting from the magnetic modification can be expected to decrease the electrostatic repulsion

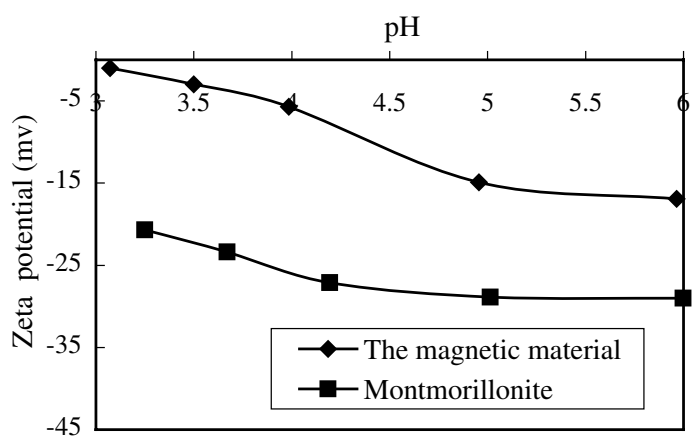

Fig. 2. The zeta potentials of the magnetic material and montmorillonite.

Table 1

The $\sigma_{\mathrm{s}}$, SSAs, pore volume and mean pore diameter of montmorillonite, the magnetic material, and regenerated magnetic material

\begin{tabular}{llclc}
\hline Sample & $\begin{array}{l}\sigma_{\mathrm{s}} \\
\left(\mathrm{emu} \mathrm{g}^{-1}\right)\end{array}$ & $\begin{array}{l}\text { SSA } \\
\left(\mathrm{m}^{2} \mathrm{~g}^{-1}\right)\end{array}$ & $\begin{array}{l}\text { Pore volume } \\
\left(\mathrm{ml} \mathrm{g}^{-1}\right)\end{array}$ & $\begin{array}{l}\text { Mean pore } \\
\text { diameter }(\mathrm{nm})\end{array}$ \\
\hline Montmorillonite & 0 & 54 & 0.20 & 15.0 \\
The magnetic material & 3.9 & 115 & 0.26 & 9.1 \\
Regenerated magnetic material & 3.9 & 110 & 0.24 & 9.0 \\
\hline
\end{tabular}


between the adsorbent particles and facilitate the separation of adsorbent from the solution. Furthermore, because of its much higher zeta potentials, the magnetic material can be expected to reduce the repulsion between its particles and negatively charged substances and enhance the removal of these substances from liquid solutions.

\subsection{Adsorption of humic acid to the magnetic material}

The kinetic study results are shown in Fig. 3. It can be seen that the equilibrium time of humic acid adsorption is $3.5 \mathrm{~h}$ and the removal efficiency reaches $94 \%$.

The effect of $\mathrm{pH}$ on the adsorption of humic acid is shown in Fig. 4. As can be seen from Fig. 4, the amount of humic acid adsorbed to the magnetic material remains almost the same during the $\mathrm{pH}$ range of 3.1-6.1 and a high removal efficiency of about $96 \%$ has been observed. At $\mathrm{pH}>6.1$, humic acid adsorbed decreases with the increase in $\mathrm{pH}$. An increase in $\mathrm{pH}$ from 6.1 to 9.0 results in a decrease from $96 \%$ to $15 \%$ in the removal efficiency of

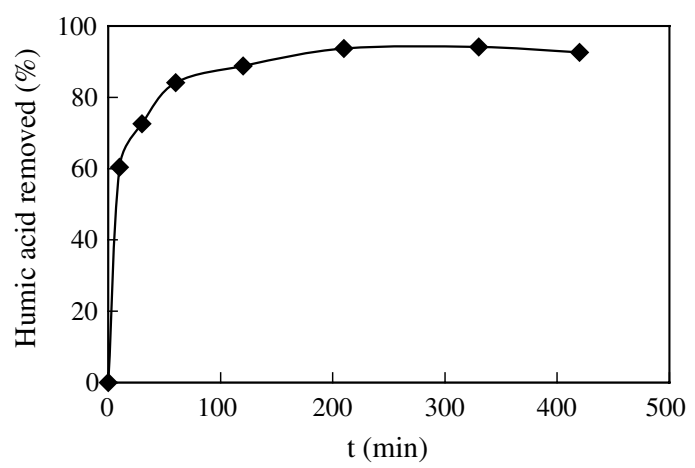

Fig. 3. Effect of contact time on humic acid adsorption $\left(\mathrm{pH}=6.0, m=0.05 \mathrm{~g}, C_{\mathrm{Na}}=0.02 \mathrm{M}, C=5.0 \mathrm{mg} \mathrm{l}^{-1}\right)$.

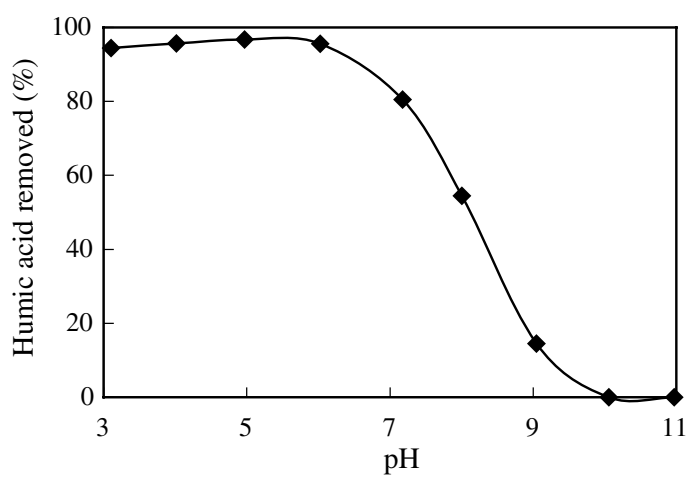

Fig. 4. Effect of $\mathrm{pH}$ on the adsorption $(m=0.05 \mathrm{~g}, C=$ $\left.4.4 \mathrm{mg} \mathrm{l}^{-1}, C_{\mathrm{Na}}=0.02 \mathrm{M}, t=3.5 \mathrm{~h}\right)$. humic acid. The dependence of adsorption on $\mathrm{pH}$ values can be explained by two mechanisms: (1) pH of the solution affects the surface charge of the magnetic material and the ionization of humic acid. The higher the $\mathrm{pH}$, the greater will be the dissociation of the functional groups $-\mathrm{COOH}$ and $-\mathrm{COH}$ to $-\mathrm{COO}^{-}$and $-\mathrm{CO}^{-}$. The net effect will result in an increase in negative charges on humic acid (Liu and Gonzalez, 1999). At higher $\mathrm{pH}$ values, the electrostatic repulsion between the negative charges on the magnetic material and humic acid repels the humic acid from the surface of the magnetic material and the increase of negative charge densities on both the adsorbent and adsorbate with increasing $\mathrm{pH}$ results in the decrease in adsorption. (2) At lower $\mathrm{pH}$ values, carboxylic groups on the humic acid molecules are protonated, minimizing the intramolecular electrostatic repulsion and contracting the humic acid molecules. Humic acid may exist in a spherical structure at lower $\mathrm{pH}$ but exist in a rather linear or stretched structure at higher $\mathrm{pH}$ (Vermeer et al., 1998; Jones and Bryan, 1998). Decrease of the molecular volume can facilitate the adsorption process due to greater availability of pores where humic acid molecules can penetrate (Bjelopavlic et al., 1999).

The adsorption of humic acid to the magnetic material maybe is the ligand exchange reaction between humic acid molecules and the magnetic material. This process involves the proton shift reactions on the adsorbent surface and the ligand exchange between carboxylic groups of humic acid molecules and adsorbent surface. In aqueous solution, the following proton shift reactions exist on the surface of the adsorbent (McBride, 1994; Schindler and Stumm, 1987; Abate and Masini, 2003):

$$
\begin{aligned}
& \text { Ad } \mathrm{OH}_{2}^{+}+\mathrm{H}_{2} \mathrm{O} \rightleftharpoons \text { 标OH }+\mathrm{H}_{3} \mathrm{O}^{+} \\
& \text {才 } \mathrm{OH}+\mathrm{H}_{2} \mathrm{O} \rightleftharpoons \text { 才 } \mathrm{O}^{-}+\mathrm{H}_{3} \mathrm{O}^{+}
\end{aligned}
$$

The ligand exchange then may occur between carboxylic groups of humic acid molecules and adsorbent surface (Sposito, 1989; Murphy and Zachara, 1995; Abate and Masini, 2003):

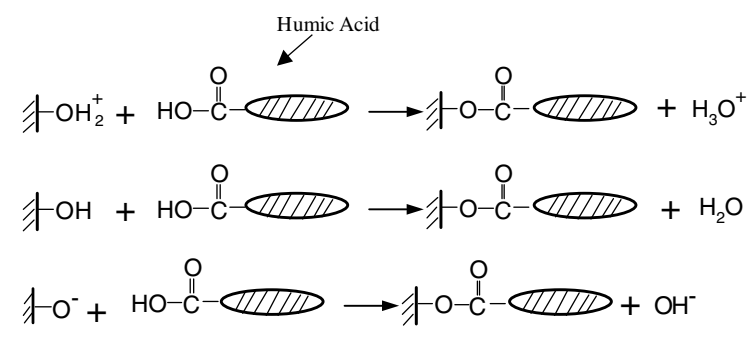




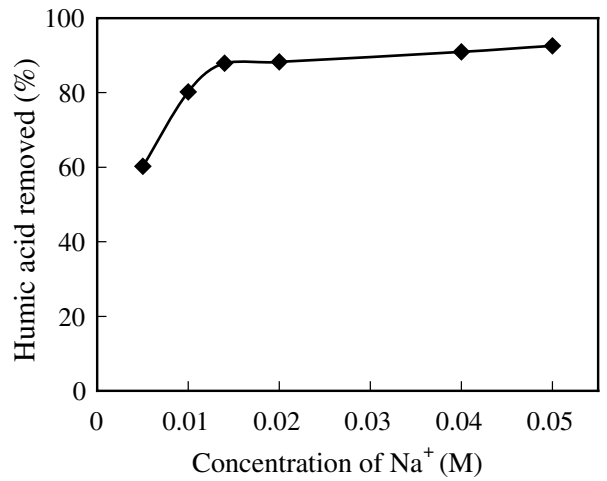

Fig. 5. The effect of ionic strength on the adsorption $(\mathrm{pH}=6.0$, $m=0.05 \mathrm{~g}, t=3.5 \mathrm{~h}, C=4.6 \mathrm{mg} \mathrm{l}^{-1}$ ).

As discussed earlier, adsorption of humic acid seems to be a charge-related adsorption phenomenon. Ionic strength is an important factor affecting the adsorption in such kind of phenomenon. So the effect of ionic strength on the adsorption was studied. The ionic strength of the solution was adjusted with $\mathrm{NaCl}$. The results are shown in Fig. 5. As can be seen, an increase in ionic strength results in an increase in the adsorption. The increase of adsorption with the increase in the ionic strength can be explained by several mechanisms (Abate and Masini, 2003; Zhang and Bai, 2003): (1) the addition of salt results in the compression of the diffuse double layer and charge neutralization on the magnetic material, which would facilitate the ligand exchange mechanism; (2) the increase of ionic strength causes a decrease of molecular volume of humic acid due to minimization of the electrostatic repulsion between ionized oxygen groups. The decrease of molecular volume of the humic acids facilitates the adsorption; (3) at $\mathrm{pH}$ above the point of zero charge of adsorbent particles, the electrostatic interactions between negatively charged adsorbent particles and the negatively charged oxygen groups were repulsive. The addition of salt results in the screening of the surface charge of both adsorbent and adsorbate. Thus the electrostatic repulsion can be reduced by increasing the ionic strength of the solution due to this screening effect.

The adsorption isotherm is shown in Fig. 6. The isotherm study shows that the adsorption capacity exceeds $98 \mathrm{mg} \mathrm{g}^{-1}$. The data can be fitted to Langmuir isotherm model with a coefficient of 0.96 .

\subsection{Thermal regeneration tests}

Important aspects of thermal regeneration are the time and temperature required to achieve good regeneration efficiency. The effect of regeneration temperature on adsorption properties of regenerated magnetic adsorbent is demonstrated in Fig. 7. The regeneration tests

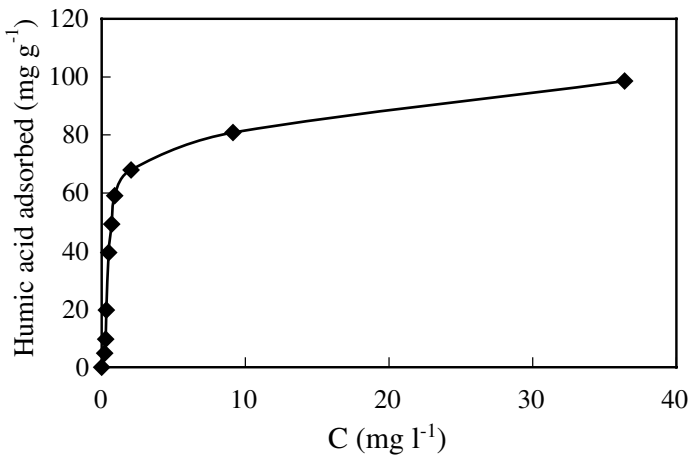

Fig. 6. Isotherm of humic acid adsorption $(\mathrm{pH}=5.0, m=$ $\left.0.05 \mathrm{~g}, C_{\mathrm{Na}}=0.02 \mathrm{M}, t=3.5 \mathrm{~h}\right)$.

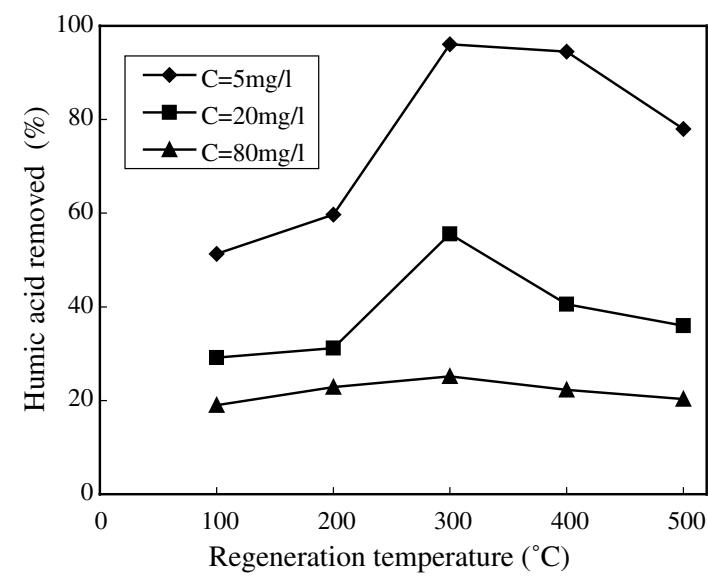

Fig. 7. Humic acid removal of regenerated magnetic adsorbent as a function of regeneration temperature $(\mathrm{pH}=4.8, t=3.5 \mathrm{~h}$, $\left.m=0.05 \mathrm{~g}, C_{\mathrm{Na}}=0.02 \mathrm{M}\right)$.

were carried out by calcining the exhausted magnetic adsorbent at certain temperatures for $3 \mathrm{~h}$. As can be seen, at all the concentrations studied, the humic acid removal increases with an increase in the regeneration temperature and reaches a peak approximately around $300{ }^{\circ} \mathrm{C}$. After that, the removal begins to fall off. From the results revealed in this figure, it could be concluded that $300^{\circ} \mathrm{C}$ is a good temperature for regeneration.

Fig. 8 demonstrates the humic acid removal of regenerated magnetic adsorbent as a function of regeneration time at constant temperature $300{ }^{\circ} \mathrm{C}$. The removal is seen to increase with the regeneration time and reaches a peak approximately around $3 \mathrm{~h}$. Hence a regeneration time of $3 \mathrm{~h}$ was adopted for the present study and can be recommended for regeneration purpose.

A test with the $\mathrm{Nd}-\mathrm{Fe}-\mathrm{B}$ magnet showed that the regenerated magnetic adsorbent was still magnetic and completely attracted to the magnet. The magnetization measurements showed that the $\sigma_{\mathrm{s}}$ of the regenerated 


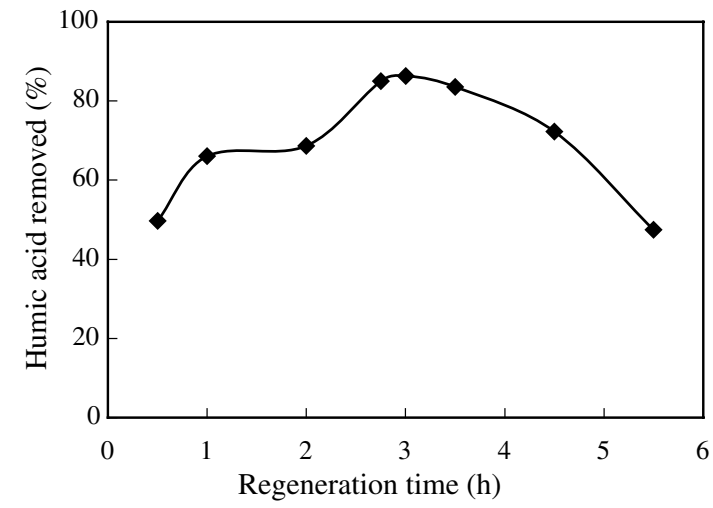

Fig. 8. Humic acid removal of regenerated magnetic adsorbent as a function of regeneration time $(\mathrm{pH}=5.0, m=0.05 \mathrm{~g}$, $\left.C=20 \mathrm{mg} \mathrm{l}^{-1}, C_{\mathrm{Na}}=0.02 \mathrm{M}\right)$.

magnetic adsorbent is $3.9 \mathrm{emu} \mathrm{g}^{-1}$ (magnetic fiel$\mathrm{d}=20000 \mathrm{Oe}$ ). The BET data of the regenerated adsorbent are shown in Table 1. It can be seen that the SSAs, pore volume and mean pore diameter decrease slightly after regeneration. To further verify the regeneration efficiency of spent magnetic adsorbent by the procedure adopted in the present study and at the recommended regeneration conditions of $300^{\circ} \mathrm{C}$ for $3 \mathrm{~h}$, the humic acid removal of regenerated magnetic adsorbent was studied and was compared to that of as-prepared magnetic adsorbent. The removal efficiency of the regenerated magnetic adsorbent from 5, 20 and $80 \mathrm{mg}^{-1}$ humic acid solution are $96 \%, 85 \%$ and $23 \%$, while that of the as-prepared magnetic adsorbent's are $92 \%, 90 \%$ and $24 \%$. These results show that the regenerated adsorbent approximately has as good adsorption capacities as asprepared magnetic adsorbent and indicate that this kind of magnetic adsorbent can be successfully regenerated by a thermal process.

\section{Conclusions}

(1) Montmorillonite- $\mathrm{Cu}(\mathrm{II}) / \mathrm{Fe}(\mathrm{III})$ oxides magnetic material has been successfully prepared for the removal of humic acid. It has higher zeta potential than montmorillonite. The specific saturation magnetization and specific surface area of the magnetic material are $3.9 \mathrm{emu} \mathrm{g}^{-1}$ and $115 \mathrm{~m}^{2} \mathrm{~g}^{-1}$, respectively. The increased specific surface area, pore volume and decreased mean pore diameter of the magnetic material comparing to the raw montmorillonite suggests the formation of microporous system in the magnetic material.

(2) The magnetic material is effective for the removal of humic acid. At $\mathrm{pH} 6.1,96 \%$ removal was observed from $4.4 \mathrm{mg} \mathrm{l}^{-1}$ humic acid solution containing $0.02 \mathrm{M}$ $\mathrm{NaCl}$. The adsorption is $\mathrm{pH}$ and ionic dependent.
Adsorption is favored at lower $\mathrm{pH}$ values and dissolved $\mathrm{NaCl}$ can enhance the adsorption. The adsorption mechanism of humic acid to the magnetic material was suggested to be the ligand exchange reaction between carboxylic groups of humic acid molecules and the magnetic material. The dependence of adsorption on $\mathrm{pH}$ values is probably due to the effect of $\mathrm{pH}$ on the surface charge of the magnetic material and the ionization of humic acid and the minimization of humic acid molecules at lower $\mathrm{pH}$ values. The increase of adsorption with the increase of ionic strength is probably due to the compression of the diffuse double layer and charge neutralization, the compression of the molecular volume of humic acid and the screening of the surface charge of both adsorbent and adsorbate by salt.

(3) The magnetic material can be thermally regenerated. The temperature and time required to achieve good regeneration efficiency were determined to be $300{ }^{\circ} \mathrm{C}$ and $3 \mathrm{~h}$, respectively. The regenerated adsorbent is still magnetic and approximately has as high specific saturation magnetization and good adsorption capacities as the as-prepared adsorbent.

\section{Acknowledgement}

Funded by National Sciences Foundation of China (40273044).

\section{References}

Abate, G., Masini, J.C., 2003. Influence of $\mathrm{pH}$ and ionic strength on removal processes of a sedimentary humic acid in a suspension of vermiculite. Colloids Surf. A 226, 25-34.

Bjelopavlic, M., Newcombe, G., Hayes, R., 1999. Adsorption of NOM onto Activated Carbon: effect of surface charge, ionic strength, and pore volume distribution. J. Colloid Interf. Sci. 210, 271-280.

Booker, N.A., Keir, D., Priestley, A., Rithchie, C.D., Sudarmana, D.L., Woods, M.A., 1991. Sewage clarification with magnetite particles. Water Sci. Technol. 23, 1703-1712.

Jones, M.N., Bryan, N.D., 1998. Colloidal properties of humic substances. Adv. Colloid Interf. Sci. 78, 1-48.

Lee, J., Isobe, T., Senna, M.J., 1996. Preparation of ultrafine $\mathrm{Fe}_{3} \mathrm{O}_{4}$ particles by precipitation in the presence of PVA at high pH. J. Colloid Interf. Sci. 177, 490-494.

Liu, A., Gonzalez, R.D., 1999. Adsorption/desorption in a system consisting of humic acid, heavy metals, and clay minerals. J. Colloid Interf. Sci. 218, 225-232.

Mak, S.Y., Chen, D.H., 2004. Fast adsorption of methylene blue on polyacrylic acid-bound iron oxide magnetic nanoparticles. Dyes Pigments 61, 93-98.

McBride, M.B., 1994. Environmental Chemistry of Soils. Oxford University Press, Oxford.

Murphy, E.M., Zachara, J.M., 1995. The role of sorbed humic substances on the distribution of organic and inorganic contaminants in groundwater. Geoderma 67, 103-124. 
Oliveira, L.C.A., Rios, R.V.R.A., Fabris, J.D., Garg, V.K., Sapag, K., Lago, R.M., 2002. Activated carbon/iron oxide magnetic composites for the adsorption of contaminants in water. Carbon 40, 2177-2183.

Oliveira, L.C.A., Rios, R.V.R.A., Fabris, J.D., Sapag, K., Garg, V.K., Lago, R.M., 2003. Clay-iron oxide magnetic composites for the adsorption of contaminants in water. Appl. Clay Sci. 22, 169-177.

Peng, X., Luan, Z., Chen, F., Tian, B., Jia, Z., 2005. Adsorption of humic acid to pillared bentonite. Desalination 174, 135 143.

Schindler, P.W., Stumm, W., 1987. In: Stumm, W. (Ed.), Aquatic Surface Chemistry. Wiley, New York.

Skoutelas, A.P., Karakassides, M.A., Petridis, D., 1999. Magnetically modified $\mathrm{Al}_{2} \mathrm{O}_{3}$ pillared clays. Chem. Mater. 11, 2754-2759.
Sposito, G., 1989. The Chemistry of Soils. Oxford University Press, Oxford.

Vermeer, A.W.P., van Riemsdijk, W.H., Koopal, L.K., 1998. Adsorption of humic acid to mineral particles 1: Specific and electrostatic interactions. Langmuir 14, 28102819.

Wu, P.X., Liao, Z.W., Zhang, H.F., Guo, J.G., 2001. Adsorption of phenol on inorganic-organic pillared montmorillonite in polluted water. Environ. Int. 26, 401-407.

Yokoi, H., Yagishita, K., Nakanishi, Y., 1990. Studies on the formation of magnetic colloidal dispersions in the presence of poly(vinyl alcohol). Bull. Chem. Jpn. 63, 746-748.

Zhang, X., Bai, R., 2003. Mechanisms and kinetics of humic acid adsorption onto chitosan-coated granules. J. Colloid Interf. Sci. 264, 30-38. 